\title{
Aggressive genetic "double-hit" B-cell lymphoma following renal transplantation: case report
}

\author{
Nathanael G. Bailey • Bryan L. Betz • Diane Roulston • \\ Kojo S. J. Elenitoba-Johnson • Megan S. Lim
}

Received: 23 March 2012 / Accepted: 9 May 2012 / Published online: 27 May 2012

(C) Springer-Verlag 2012

\begin{abstract}
B-cell lymphomas with two oncogenic chromosomal translocations ("double-hit" lymphomas [DHL]) often exhibit morphologic and immunophenotypic features intermediate between conventional diffuse large B-cell lymphoma and Burkitt's lymphoma (BL). DHL are highly aggressive neoplasms that respond poorly to current treatment strategies. A case of DHL that arose in a patient with a history of renal transplantation, diagnosed in a skin biopsy, is described. The lymphoma had morphologic features reminiscent of BL; however, in addition to the IGH@-MYC fusion, BCL6 was translocated to chromosome 13 in the presence of a complex karyotype. This case exhibits very unusual features: lymphomas with both $M Y C$ and BCL6 translocations are rare, and posttransplant DHL have virtually never been described. The importance of identifying patients with DHL is emphasized, as these patients require alternative therapeutic approaches.
\end{abstract}

Keywords Double-hit · Lymphoma $\cdot$ Posttransplant lymphoproliferative disorder · BCL6

\section{Introduction}

B-cell lymphomas harboring two or more chromosomal translocations involving genes recurrently implicated in lymphomagenesis are commonly referred to as "doublehit" lymphomas (DHL) [1]. Most commonly, these lymphomas have both BCL2 and MYC rearrangements; however,

N. G. Bailey $(\triangle) \cdot$ B. L. Betz $\cdot$ D. Roulston •

K. S. J. Elenitoba-Johnson • M. S. Lim

Department of Pathology, University of Michigan,

1301 Catherine Street, SPC 5602,

Ann Arbor, MI 48109, USA

e-mail: ngbailey@med.umich.edu
$M Y C$ rearrangements have also been described in conjunction with $B C L 6$ and $C C N D 1$ translocations [2]. DHL have a very aggressive clinical course and respond poorly to current standard therapies [1, 3, 4]. Many of these lymphomas have morphologic and immunophenotypic features intermediate between diffuse large B-cell lymphoma (DLBCL) and Burkitt's lymphoma (BL). In the most recent WHO classification, a new diagnostic category "B-cell lymphoma, unclassifiable, with features intermediate between diffuse large B-cell lymphoma and Burkitt's lymphoma" (I-DLBCL/BL) was introduced [1], and most cases of DHL are now expected to be classified in this category [5]. Due to their relative frequency, $B C L 2 / M Y C$ DHL are the best-characterized DHL. Less is known about the clinicopathologic features of $B C L 6 / M Y C$ DHL, and only a limited number have been described in the literature $[2,6]$.

Here, we describe a case of $B C L 6 / M Y C$ DHL that arose in a patient 17 years after renal transplantation. This case adds to the limited literature regarding $B C L 6 / M Y C$ DHL. The importance of classical cytogenetic and fluorescence in situ hybridization (FISH) for proper classification of highgrade B-cell neoplasms is emphasized, and the lymphoma's possible relationship with the patient's renal transplant is discussed.

\section{Case report}

The patient was a 57 year-old male who presented to the emergency department with complaints of abdominal pain. He had felt ill for the previous 2 weeks, with lethargy, dyspnea, and diaphoresis. The abdominal pain had arisen and become increasingly severe over the course of the previous week. He had no fever, nausea, vomiting, or diarrhea. The patient's medical history was notable for a cadaveric renal 
transplant 17 years ago due to end-stage renal disease secondary to Alport syndrome. He had no complaints of flank pain, hematuria, or dysuria. The patient's renal function had been stable for years, and he had been maintained on cyclosporine for immunosuppression. He additionally had chronic hepatitis $\mathrm{C}$ infection, with stable liver function. An abdominal CT revealed diffuse stranding and nodularity in the bowel mesentery and omentum. He had a 1-cm subcutaneous nodule on the left upper abdomen that was new, nontender, and not pruritic. The nodule was biopsied. After receiving the results of the skin biopsy, a bone marrow aspiration and biopsy were performed, and the patient was started on an intensive hyperCVAD chemotherapeutic regimen, with the addition of rituximab. His treatment was complicated by his underlying comorbidities. Although the tumor initially responded to therapy, the patient developed sepsis, multiorgan failure, and died 6 months after initial diagnosis.

\section{Methods}

Sections of the skin biopsy were fixed in B5 and $10 \%$ neutral buffered formalin. The bone marrow biopsy was fixed in B5 and formalin with subsequent decalcification. Both specimens were processed and embedded in paraffin using routine histologic techniques. Sections were stained with hematoxylin and eosin. Bone marrow aspirate preparations were stained with Wright-Giemsa.

Immunohistochemical stains were performed using an automated immunostainer (Ventana Medical Systems, Tuscon, AZ, USA). Immunohistochemical stains used included CD3,
CD20, CD10, BCL6, Ki-67 (Ventana Medical Systems, Tuscon, AZ, USA), and BCL2 (EMD4 Biosciences, San Diego, CA, USA). In situ hybridization for Epstein-Barr early RNA (EBER, Ventana Medical Systems, Tuscon, AZ, USA) was performed. All control tissues stained appropriately.

The bone marrow sample was processed using standard cytogenetic techniques. Trypsin-Giemsa-banded metaphase cells were analyzed at 400 band resolution level. Interphase FISH was performed on the skin sample, following deparaffinization, using Vysis LSI BCL6 (ABR) Dual Color, Break Apart Rearrangement Probe and Vysis LSI MYC Dual Color Break Apart Rearrangement Probe (Abbot Molecular, Des Plaines, IL, USA). FISH was additionally performed on the bone marrow aspirate to assess the $L C P 1$ locus using a break-apart strategy. BAC clones RP11-71 J12 and RP11247 M1 (BlueGnome, Cambridge, UK) were differentially fluorescently labeled and hybridized to metaphase cells.

\section{Results}

Histology

The cutaneous nodule was composed of a dermal and subcutaneous infiltrate of monomorphic medium to large lymphocytes with variably prominent nucleoli, a high mitotic rate, and "starry sky" appearance (Fig. 1a-c). The bone marrow was replaced by the same process. Cytologic preparations of the bone marrow biopsy showed that the cells had extensive cytoplasmic vacuolization (Fig. 1d).
Fig. 1 Histologic features of the case. a The skin contains a dermal and subdermal lymphoid infiltrate $(\mathrm{H} \& \mathrm{E}$, $\times 40$ ). b The lymphocytes infiltrate the subcutaneous fat. A "starry-sky" appearance is evident $(\mathrm{H} \& \mathrm{E}, \times 100)$. c The lymphocytes are monomorphic, medium to large, and have variably prominent nucleoli. Mitotic figures and background debris-laden macrophages are prominent $(\mathrm{H} \& \mathrm{E}, \times 600)$. d Cytologic preparations of the bone marrow aspirate demonstrate that the lymphocytes have multiple small cytoplasmic vacuoles. Wright-Giemsa, $\times 1,000$
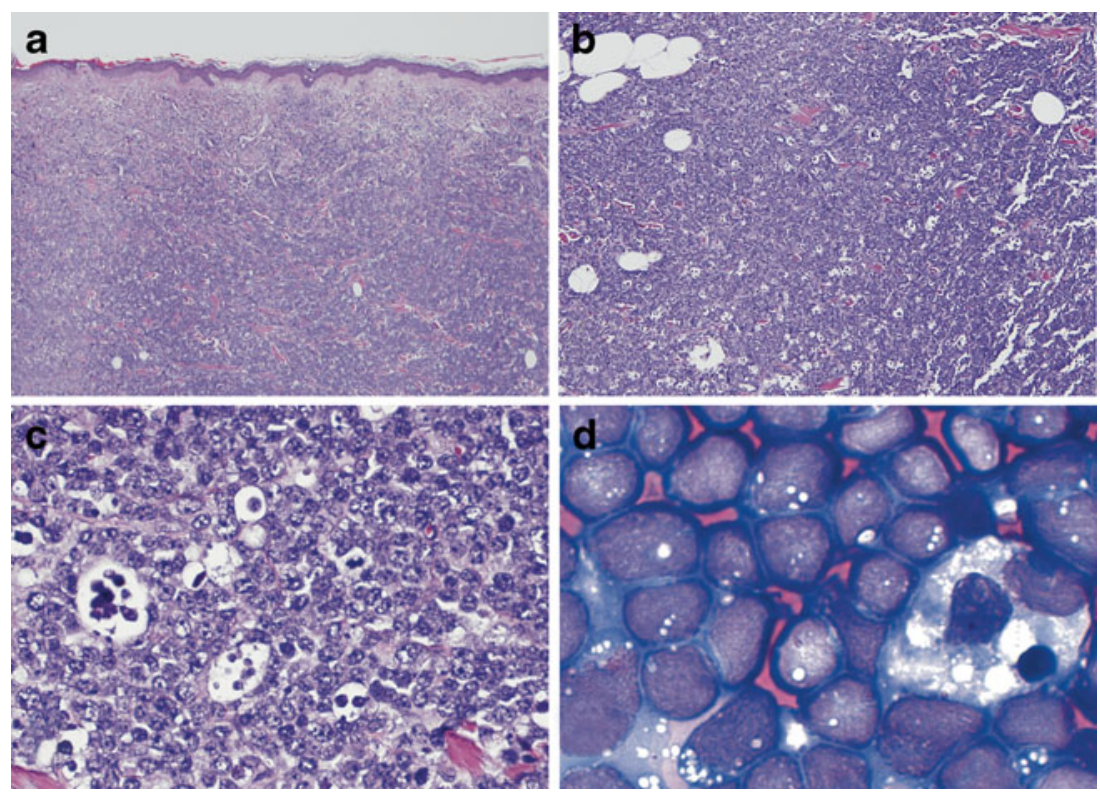
Immunohistochemistry

The neoplastic infiltrate consisted of CD20-positive B cells with coexpression of CD10. The cells expressed BCL6, weakly expressed BCL2, and had a proliferation fraction that surpassed $95 \%$ by Ki-67 staining (Fig. 2). In situ hybridization for Epstein-Barr early RNA (EBER) was negative, as were serologic studies for EBV.

\section{Cytogenetics}

Metaphase cytogenetics revealed a complex karyotype: 47, $\mathrm{XY},-3, \mathrm{t}(3 ; 13)(\mathrm{q} 27 ; \mathrm{q} 14),+\operatorname{der}(3) \mathrm{t}(3 ; 13)(\mathrm{q} 27 ; \mathrm{q} 14), \operatorname{del}(6)$ $(\mathrm{q} 21 \mathrm{q} 25),+7, \mathrm{t}(8 ; 14)(\mathrm{q} 24 ; \mathrm{q} 32)$ (Fig. 3a). FISH was performed to further characterize the identified translocations. Break-apart probes for MYC at 8q24 and BCL6 at 3q27 both demonstrated split signals, confirming that $M Y C$ and $B C L 6$ were involved in the translocations (Fig. 3b,c). By metaphase cytogenetics, the $M Y C$ locus was rearranged with 14q32, the location of the IGH@ locus. The BCL6 probes yielded an unusual pattern consisting of two green (centromeric) signals and only a single red (telomeric) signal. This pattern is consistent with the karyotypic findings of a duplicated derivative chromosome 3 containing material from chromosome 13, along with loss of the residual normal chromosome 3 . The translocation partner located at $13 \mathrm{q} 14$ for $B C L 6$ was unknown. The only previously reported $B C L 6$ translocation partner in this chromosomal region is LCP1 [7]; therefore, this locus was examined. Break-apart FISH probes assessing $L C P 1$ revealed a normal, dual fusion signal pattern (data not shown).

\section{Discussion}

We have described a case of DHL containing both BCL6 and $M Y C$ rearrangements. The lymphoma was systemic at time of presentation and was diagnosed through a skin biopsy. The morphologic features of the lymphoma were suggestive of BL; however, the immunophenotype was atypical for this diagnosis. The application of genetic techniques allowed us to establish that the lymphoma was not classical BL and that it should rather be classified as IDLBCL/BL. The patient's remote history of a renal transplantation and continued immunosuppression with singleagent cyclosporine additionally raises the possibility that the lymphoma should be considered a posttransplant lymphoproliferative disorder (PTLD).

According to current WHO criteria, a nonindolent lymphoma that arises in a transplant recipient is, by definition, PTLD [8]. Given the high-grade morphology of the current case, it would be classified as monomorphic PTLD (MPTLD) according to WHO criteria. Several features of this case are unusual for M-PTLD, however. Although adult renal transplant patients are certainly at increased risk for PTLD, the incidence is low compared with other transplant types, estimated at $0.4-2.0 \%$ [9]. While EBV-negative MPTLD is associated with longer latency posttransplant than other types of PTLD, 17 years is atypical [10]. Additionally, although MYC rearrangements are seen in PTLD, BCL6 rearrangements are uncommon; and DHL, as previously defined, are vanishingly rare [11-13]. To the best of our knowledge, this is the first case of a $B C L 6 / M Y C$ DHL that has been described in the posttransplant setting. Therefore, it is unclear whether this lymphoma is truly posttransplantrelated.
Fig. 2 Immunohistochemical features. The lymphocytes strongly express CD20 (a, $\times 100)$, with weak BCL2 expression $(\mathbf{b}, \times 200)$. BCL6 is expressed $(\mathbf{c}, \times 400)$, and $\mathrm{Ki}-67$ staining demonstrates a proliferation fraction of $>95 \%$ $(d, \times 400)$
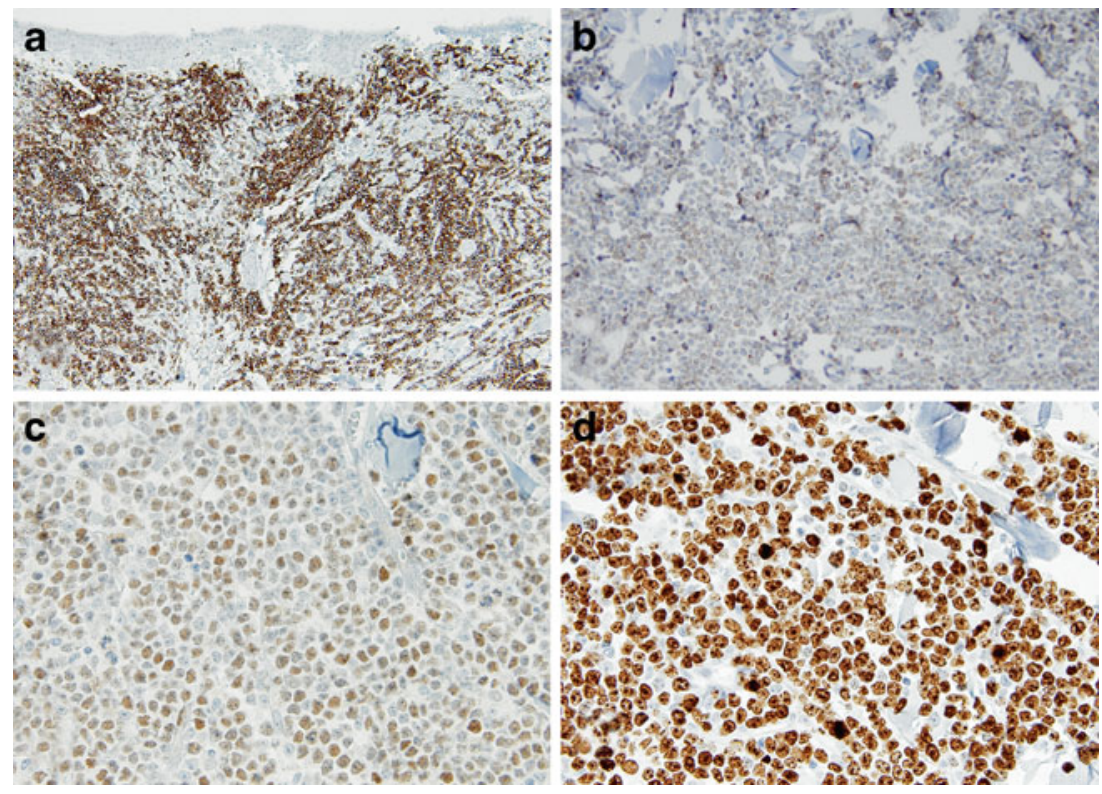
Fig. 3 Cytogenetic features. A complex karyotype of 47,XY,$3, \mathrm{t}(3 ; 13)(\mathrm{q} 27 ; \mathrm{q} 14),+\operatorname{der}(3) \mathrm{t}$

$(3 ; 13)(\mathrm{q} 27 ; \mathrm{q} 14), \operatorname{del}(6)$

(q21q25), +7, t(8;14)(q24;q32)

was identified (a). The $\mathrm{t}(3 ; 13)$

and duplicated der(3)

containing BCL6

rearrangements are denoted by arrowheads. Arrows denote the $\mathrm{t}(8 ; 14)$ that lead to IGH@-MYC fusion. Note that this particular cell additionally exhibited random loss of one

chromosome 18. Fluorescence in situ hybridization for $M Y C$ (b) and $B C L 6$ (c). The $M Y C$ break-apart probe shows one red, one green, and one fusion (yellow) signal in most cells, indicating $M Y C$ rearrangement. The $B C L 6$ break-apart probe shows an abnormal pattern with two green, one red, and no fusion signals in most cells. This is consistent with the karyotypic findings of a duplicated der $(3) \mathrm{t}(3 ; 13)$ and concomitant loss of the normal chromosome 3 a
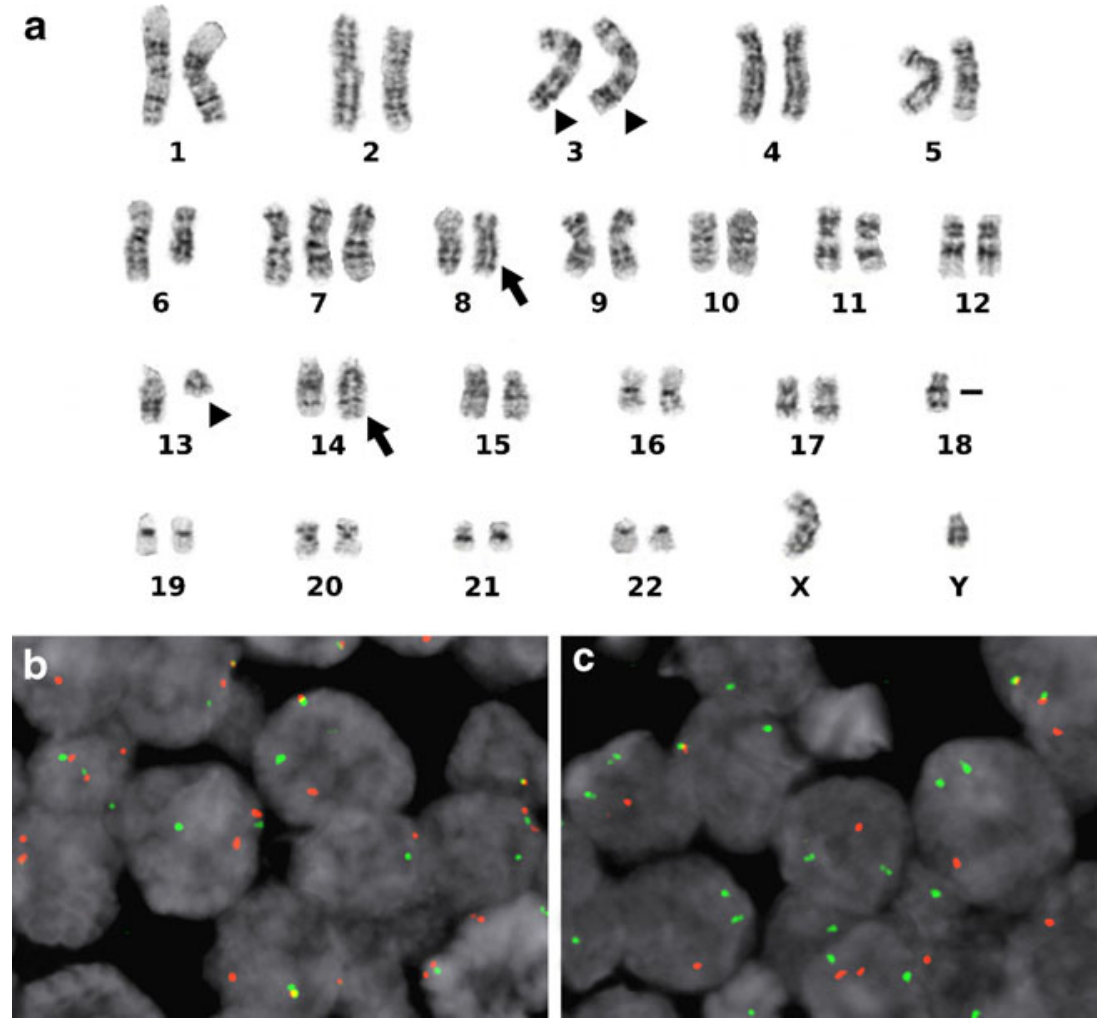

Some of the morphologic features as well as the expression of CD10, BCL6, high proliferation rate, and the documentation of an IGH@-MYC fusion by FISH suggest Burkitt's lymphoma. These findings are not specific for $\mathrm{BL}$, as DLBCL may contain $M Y C$ rearrangements [1]. Additionally, several features argue against a diagnosis of classical BL, primarily the expression of BCL2 and the cytogenetic findings. Cases of true BL as defined by gene expression have relatively few genetic changes $[1,3]$. BL harbor fewer than six genetic aberrations as demonstrated by array comparative genomic hybridization [3] or two or fewer abnormalities in addition to the $\mathrm{t}(8 ; 14)$ by lowerresolution metaphase karyotyping [14]. Our patient's lymphoma contained five karyotypically recognizable aberrations in addition to the $\mathrm{t}(8 ; 14)$, indicating that it is not strictly BL.

DHL contain translocations involving $B C L 2, B C L 6$, or $C C N D 1$ in addition to a $M Y C$ translocation $[1,2]$. Although many DHL are morphologically suggestive of BL, they are now classified as I-DLBCL/BL and should not be diagnosed as $\mathrm{BL}[1,5]$. DHL with translocations involving both $M Y C$ and $B C L 2$ are the most common and, therefore, the best characterized in the literature [2, 4]. In BCL2/MYC DHL, the $M Y C$ rearrangement is usually a progression-related secondary genetic change in a lymphoma harboring a $B C L 2$ rearrangement [2]. These lymphomas are highly aggressive and do not respond well to current therapy $[1,3,4]$. Recent studies including the cases from the Mitelman database [15] have examined the clinical features and outcomes of $B C L 6 / M Y C$ DHL $[2,6]$. Interestingly, so-called "triple-hit" lymphomas with translocations involving $B C L 2, B C L 6$, and $M Y C$ may be more common than those containing only $B C L 6$ and MYC [2]. Many of the reported BCL6/MYC DHL had morphologic features of BL, and they have had an aggressive clinical course [6]. It is unclear if $B C L 6 / M Y C$ and $B C L 2 / M Y C$ DHL outcomes differ due to the limited number of cases studied and the possibility that some reported $B C L 6 / M Y C$ cases actually represent unrecognized $B C L 2 / B C L 6 / M Y C$ triple-hit lymphomas [2].

We carried out FISH to determine the presence of the previously reported $L C P 1-B C L 6$ fusion [7]. The break-apart strategy used revealed a normal, dual fusion signal pattern, excluding $L C P 1$ as a translocation partner. Given the unbalanced karyotype, this result also indicates that the partner gene is located telomeric to $L C P 1$ on chromosome 13 . No other BCL6 fusion partners have been described in this region, according to the Mitelman database [15].

This patient's poor outcome in the face of treatment with intensive chemotherapy underscores the fact that new therapeutic modalities are needed to effectively treat patients with these aggressive lymphomas. Cytogenetic and molecular techniques are required for the appropriate classification of these neoplasms. Metaphase cytogenetic assessments are not routinely performed on lymphoma samples at many 
centers; however, cytogenetic results are important for the correct classification of these tumors. If feasible, tumor specimens with a clinical suspicion of a high-grade lymphoma should be sent for metaphase cytogenetics, particularly in adult patients. Interphase FISH studies for $B C L 2, B C L 6$, and $M Y C$ can be performed following formalin fixation and paraffin-embedding and should be pursued for all B-cell lymphomas with aggressive features or those that are suggestive of BL. The identification of DHL is critical so that patients with this aggressive disease receive appropriate counseling regarding their prognosis and become candidates for investigational therapies.

Conflict of interest The authors declare that they have no conflict of interest.

\section{References}

1. Kluin PM, Harris NL, Stein H, Leoncini L, Raphaël M, Campo E, Jaffe ES (2008) B-cell Lymphoma, unclassifiable, with features intermediate between diffuse large B-cell lymphoma and Burkitt lymphoma. In: Swerdlow SH et al (eds) WHO classification of tumours of haematopoietic and lymphoid tissues. IARC, Lyon, pp $265-6$

2. Aukema SM, Siebert R, Schuuring E, van Imhoff GW, Kluin-Nelemans H, Boerma E, Kluin PM (2011) Double hit Bcell lymphomas. Blood 117:2319-2331

3. Hummel M, Bentink S, Berger H, Klapper W, Wessendorf S, Barth TFE, Bernd H, Cogliatti SB, Dierlamm J, Feller AC, Hansmann M, Haralambieva E, Harder L, Hasenclever D, Kühn M, Lenze D, Lichter P, Martin-Subero JI, Möller P, Müller-Hermelink H, Ott G, Parwaresch RM, Pott C, Rosenwald A, Rosolowski M, Schwaenen C, Stürzenhofecker B, Szczepanowski M, Trautmann H, Wacker H, Spang R, Loeffler M, Trümper L, Stein H, Siebert R, Molecular Mechanisms in Malignant Lymphomas Network Project of the Deutsche Krebshilfe (2006) A biologic definition of Burkitt's lymphoma from transcriptional and genomic profiling. N Engl J Med 354:2419-30

4. Snuderl M, Kolman OK, Chen Y, Hsu JJ, Ackerman AM, Dal Cin P, Ferry JA, Harris NL, Hasserjian RP, Zukerberg LR, Abramson JS, Hochberg EP, Lee H, Lee AI, Toomey CE, Sohani AR (2010) B-cell lymphomas with concurrent IGH-BCL2 and MYC rearrangements are aggressive neoplasms with clinical and pathologic features distinct from Burkitt lymphoma and diffuse large B-cell lymphoma. Am J Surg Pathol 34:327-40

5. Campo E, Swerdlow SH, Harris NL, Pileri S, Stein H, Jaffe ES (2011) The 2008 WHO classification of lymphoid neoplasms and beyond: evolving concepts and practical applications. Blood 117:5019-32

6. Pillai R, Sathanoori M, Swerdlow S (2011) Clinicopathologic features of double hit lymphomas with BCL6 and MYC gene rearrangements. Mod Pathol 24:315A

7. Galiègue-Zouitina $\mathrm{S}$, Quief $\mathrm{S}$, Hildebrand MP, Denis $\mathrm{C}$, Detourmignies L, Laï JL, Kerckaert JP (1999) Nonrandom fusion of L-plastin(LCP1) and LAZ3(BCL6) genes by $\mathrm{t}(3 ; 13)(\mathrm{q} 27 ; \mathrm{q} 14)$ chromosome translocation in two cases of B-cell non-Hodgkin lymphoma. Genes Chromosom Cancer 26:97-105

8. Swerdlow SH, Webber SA, Chadburn A, Ferry JA (2008) Posttransplant lymphoproliferative disorders. In: Swerdlow SH et al (eds) WHO classification of tumours of haematopoietic and lymphoid tissues. IARC, Lyon, pp 343-9

9. Caillard S, Lelong C, Pessione F, Moulin B (2006) Post-transplant lymphoproliferative disorders occurring after renal transplantation in adults: report of 230 cases from the French registry. Am J Transplant 6:2735-2742

10. Ghobrial IM, Habermann TM, Macon WR, Ristow KM, Larson TS, Walker RC, Ansell SM, Gores GJ, Stegall MD, McGregor CG (2005) Differences between early and late posttransplant lymphoproliferative disorders in solid organ transplant patients: are they two different diseases? Transplantation 79:244-7

11. Cesarman E, Chadburn A, Liu Y, Migliazza A, Dalla-Favera R, Knowles DM (1998) BCL-6 gene mutations in posttransplantation lymphoproliferative disorders predict response to therapy and clinical outcome. Blood 92:2294-2302

12. Djokic M, Le Beau MM, Swinnen LJ, Smith SM, Rubin CM, Anastasi J, Carlson KM (2006) Post-transplant lymphoproliferative disorder subtypes correlate with different recurring chromosomal abnormalities. Genes Chromosom Cancer 45:313-8

13. Vakiani E, Nandula SV, Subramaniyam S, Keller CE, Alobeid B, Murty VV, Bhagat G (2007) Cytogenetic analysis of B-cell posttransplant lymphoproliferations validates the World Health Organization classification and suggests inclusion of florid follicular hyperplasia as a precursor lesion. Hum Pathol 38:315-25

14. Seegmiller AC, Garcia R, Huang R, Maleki A, Karandikar NJ, Chen W (2010) Simple karyotype and bcl-6 expression predict a diagnosis of Burkitt lymphoma and better survival in IG-MYC rearranged high-grade B-cell lymphomas. Mod Pathol 23:909-20

15. Mitelman F, Johansson B and Mertens F. Mitelman Database of Chromosome Aberrations and Gene Fusions in Cancer (2012) Available at: http://cgap.nci.nih.gov/Chromosomes/Mitelman Accessed 19 March 2012 